\title{
Leveraging procurement-related knowledge through a Fuzzy-based DSS: a refinement of Purchasing Portfolio Models
}

\author{
Abstract. \\ Purpose. This work aims at modeling a Decision Support System (DSS) that could overcome the oversimplified, \\ subjective, compensatory decision logic of extant Purchasing Portfolio Models (PPMs) by leveraging the firms' \\ procurement-related knowledge base.
}

Design/methodology/approach. The DSS was developed through a fuzzy-based approach, whose design and application were framed within a case study in a multinational company.

Findings. The application of the fuzzy-based DSS to a product class suggests investing in the relationship with two specific suppliers and to loosen the relationship with a third one.

Research limitations/implications. Exploiting the Fuzzy Set Theory and fostering the elicitation of procurementrelated knowledge from the decision makers, the DSS effectively tackles the concerns about the existing PPMs by including strategic-oriented priorities and contextual constraints in the evaluation.

Practical implications. The recommendations in output from the DSS are feasible, more analytical, and easy to interpret, enabling knowledge sharing, group decision processes, and better decision making.

Originality/value. To our best knowledge, this manuscript is the first attempt to effectively integrate traditional PPMs with contextual, strategy-related factors to refine the purchasing directions and to make them objective.

Keywords: Purchasing; Portfolio Model; Case Study; Decision Support Systems; Fuzzy Sets; Knowledge Management; Decision making.

Article classification: Research paper.

\section{Introduction}

The effective management of knowledge is recognized as a factor fostering decision making processes (Becerra-Fernandez and Sabherwal, 2014; Giebels et al., 2015). In Supply Chain Management, an appropriate knowledge base about both the nature of the goods that must be purchased and the kind of relationship with the suppliers strongly improves the purchasing dynamics and performances (Liyanage et al., 2009; Kilpi et al., 2018). Such a knowledge base can support the purchasing decisions and strategies (Macris and Georgakellos, 2010), and its development and exploitation are strongly related to the performance and the effectiveness of the firm's purchasing function (Hult et al., 2004; Wagner et al., 2018). The support that purchasing-related knowledge management can provide to the purchasing strategic decision (e.g., fostering close working relationships, open communication and strategic planning with a limited number of suppliers) has often been embedded in Purchasing Portfolio Models (PPMs), whose role is well-established in the literature (Ellram and Carr, 1994; Montgomery et al., 2018).

PPMs (Kraljic, 1983; Syson, 1992; Hadeler and Evans, 1994; Olsen and Ellram, 1997; Pagell et al., 2010; Montgomery et al., 2018) usually aim at: better coordinating the sourcing activities by raising 
leverage and synergy (e.g., Gelderman and Van Weele, 2002; Gelderman and Semeijn, 2006); differentiating the overall purchasing strategy (e.g., Gelderman et al., 2008; Knight et al., 2014); and considering the interdependencies and trade-offs among relationships (Wagner and Johnson, 2004) by configuring and managing supplier relationships.

Kraljic's PPM (1983) has for many years been the most followed approach by large companies - e.g., Shell, Alcatel, Philips, and Siemens (Gelderman and van Weele, 2002) - in improving the overall management of the sourcing strategies and activities. Also, it has been acknowledged by scholars as a robust and recognized basis for developing similar or more advanced approaches to purchasing and supply management (cf. Kang et al., 2018).

Yet, some still unsolved aspects may limit the appropriateness of PPM recommendations:

- Extreme simplification of their decision logic, which is mostly based only on two basic dimensions: Importance of purchasing and Complexity of supply market (Dubois and Pedersen, 2002; Gelderman, 2003; Gelderman and Van Weele, 2005; Gelderman et al., 2008);

- Failure to capture context-related dimensions and other important constraints, such as: overall business strategy of the company; corporate purchasing policies; network context (Kang et al., 2012); interdependencies among products (Ritter, 2000); sustainable competitive advantage; other relevant features, e.g. product lifecycle, which might significantly impact on the final purchasing decision;

- Arbitrariness of the compensatory processes in characterizing item positioning (Gelderman and Van Weele, 2003). The adopted methods are highly sensitive to the choice of assessment dimensions, factors, and weights. Moreover, many of these variables are qualitative and they need to be judged by experts subjectively (Padhi et al., 2012; Knight et al., 2014).

Accordingly, by deeply revising a previous version of the method by Aloini et al. (2013), this paper proposes a Decision Support System (DSS) model that contributes to the PPMs literature by tackling the above-mentioned shortcomings, which might radically affect the overall users' acceptance and managerial applicability of PPMs for real purchasing decisions. In particular, the DSS model relies on the Fuzzy Set Theory (FST) - which is recognized as a valid support to supplier segmentation (Rezaei and Ortt, 2013a; b) - because it can mitigate the above-mentioned compensatory process through a more structured and objective logic ( $c f$. Zimmermann, 2013).

Thus, the main questions underlying our research are:

"How can context-related dimensions and other important constraints be involved in the portfolio model?"

"How can measurement issues, related to definition and evaluation of the variables and their aggregation, be solved?" 
Answering these questions could contribute to the state of the art by: (1) integrating and extending the Kraljic (1983) and Olsen and Ellram (1997; henceforth: O-E)'s matrices with context-related information to validate and refine the outcoming recommendations; (2) developing a fuzzy-based implementation of the O-E matrix to tackle the uncertainty in supplier positioning due to subjective judgments and weights; (3) fulfilling the suggestion by Lau et al. (2005) to improve the flexibility of the procurement-related DSSs by adding new factors that could improve the quality of decision making by taking advantage of the purchasing knowledge base.

Also, we present a case study that explores new insights related to the inclusion of the additional information in the PPMs and that provides evidence on the applicability of the proposed methodology in a real industrial context (Sigglekow, 2007). The case presents a significant experience from a multinational company operating in the field of Electric Power Systems and Alternative Energy Systems.

The paper is organized as follows: Section 2 examines PPM literature and identifies both the open issues and the research gaps; Section 3 describes the PPM modeling; Section 4 outlines the research design; Section 5 presents the case study and highlights the findings; Section 6 contains conclusions, limitations, and future developments.

\section{Theoretical background}

In this section, we analyze the state-of-the-art to frame this work within the appropriate literature. We mostly draw attention on the overall perspective of PPMs (section 2.1) and on the related recognized gaps (section 2.2).

\subsection{Purchasing Portfolio Models}

PPMs have attracted considerable interest over the last two decades (Caniels and Gelderman 2007; Day et al., 2010; Kang et al., 2018; Medeiros and Ferreira, 2018). Many authors have suggested refining the PPMs (e.g., Hadeler and Evans, 1994; Olsen and Ellram, 1997; Medeiros and Ferreira, 2018) or specializing the models according to the type of Buyer-Supplier (B-S) relationship (Bensaou, 1999; Bensaou and Anderson, 1999; Gelderman and Van Weele, 2002; Kang et al., 2018) - see Day et al. (2010) and Rezaei and Ortt (2012) for a detailed review and comparison about PPMs.

PPMs usually follow a three-step process: (I) product-based classification of components (Kralijc 1983, Olsen and Ellram, 1997; Kamann and Van Nieulande, 2010); (II) analysis of supplier and buyer relationships (Olsen and Ellram, 1997; Bensaou and Anderson, 1999; Caniel and Gelderman, 2010); (III) gathering information to establish strategies and recommendations. The famed O-E approach starts from the Kraljic matrix and goes through three similar steps:

1) Analysis of the products and their classification through a matrix (O-E matrix 1), whose dimensions are Difficulty of managing the purchase situation and Importance of the purchase (cf. Kraljic, 1983); 
2) Analysis of the supplier relationships through another matrix (O-E matrix 2), for classifying the suppliers according to two dimensions: Supplier Attractiveness and Strength of the Relationship (Olsen and Ellram, 1997);

3) Development of action plans to match the supply/product characteristics with the company needs and supplier relationships.

The following section sheds light on PPMs' limitations and on the corresponding research gaps.

\subsection{Open issues and research gaps}

PPMs have been criticized in terms of both the overall structure, since their different dimensions are only estimations of the parameters that are supposed to be measured, and their limited applicability due to several methodological aspects (Nellore and Soderquist, 2000; Dubois and Pedersen, 2002; Gelderman and Van Weele, 2005). In the following, we present a sharp literature review that classifies and analyses PPMs' shortcomings according to an "Input-Process-Output" view, which is widely used in systems analysis for describing the structure of information processing (Curry et al., 2006) and that could help in presenting the most relevant PPMs' drawbacks.

Input measurement - PPMs are sensitive to the choice of evaluation dimensions, factors, and weights (Ramsay, 1996). Often, theories do not provide procedures for selecting variables that offer complete and suitable proxy measures. Nonetheless, this is critical to a reliable and robust positioning in the portfolio matrices and strongly affects the suitability of the outcoming directions or recommendations. Traditional PPMs often fail to capture the context which companies work in and to frame it as a valuable input, although researchers (e.g., Dubois and Pedersen, 2002) consider a network perspective essential in managing B-S relationships. For example, Olsen and Ellram (1997) and Cox (1997) recommend a proactive thinking and contextualization of the proposed actions. Gelderman and Van Weele (2003) and Nellore and Soderquist (2000) agree in stating that simple recommendations and standardized blueprints are not feasible, while a deep contextualization and an ad hoc analysis including the practitioners' experience is needed for formulating effective strategies. Thus, there is the need to include additional information in the decision logic, such as the overall business strategy directions, contextrelated information about products, suppliers, and markets (Karjalainen and Salmi, 2013), and other corporate policies (e.g., sustainability).

Decision logic (Process) - An additional criticism regards the fuzziness and nascent arbitrariness of the decision logic implemented in the decision process (Knight et al., 2014), e.g. the selection of high-low decision thresholds, and the compensatory assessment in item positioning (Rezaei and Ortt, 2013a; b). These flaws often lead to independent and sometimes contradictory outcoming strategies, since the models do not analyze the interdependence between purchasing items, suppliers, or other factors (Nellore and Soderquist, 2000). 
Quality of outputs - Because of the issues concerning input measurement and decision logic, some authors suggest a wary interpretation of the PPM recommendations, especially for borderline items (Homburg, 1995). Also, they frequently advise fully customized approaches (De Boer, 1998) for criteria selection and threshold setting. Other scholars disapprove of the limited detail offered by the outcoming recommendations, which are often too synthetic and vague to be suitable for managers (Dubois and Pedersen 2002; $c f$. Hesping and Schiele, 2016).

To overcome such limitations, alternative models including new or modified evaluation dimensions have been proposed. For instance, Bensaou (1999) and Bensaou and Anderson (1999) suggest classifying suppliers according to the specific investments, the contextual profile of the product, and the characteristics of components, market, and suppliers. They also suggest considering relationship requirements, capabilities related to the suppliers, the industrial environment (as intended by Porter, 1980), and the general environment, which includes the macroeconomic, political, technological and regulatory context. Wagner and Johnson (2004) summarize and review other important factors affecting B-S relationships: the buying class, a firm's buying practices or procedures, including buying structures, and the firm's strategic aggressiveness. Terpend (2011) strongly recommends aligning the relationship with suppliers with the contextual characteristics of purchasing, in particular: aim of purchasing, overall company policy and/or strategy, entry barriers to the supply market, item substitutability, power balance between buyer and supplier, interdependence (e.g., shared or related investments), and interorganizational trust. Additional authors (e.g., Burn and Pero, 2011; Drake et al., 2013; Sidhartha et al., 2012) underline the need to consider further variables, such as product type (functional or innovative), in defining the right purchasing strategy. More recently, the literature has focused on overcoming the lack of analytical rigor of traditional analyses by suggesting a more objective methodology to classify and position commodities (e.g., Padhi et al., 2012; Montgomery et al., 2018).

Accordingly, table 1 details four scientific gaps about PPMs that emerge from the literature analysis and that this manuscript aims at filling.

Table 1. PPMs' scientific gaps

\begin{tabular}{|c|c|}
\hline Scientific gap & Description \\
\hline $\begin{array}{l}\text { MODELLING } \\
\text { ISSUES }\end{array}$ & $\begin{array}{l}\text { More appropriate selection of the analysis critical dimensions and variables (Nellore } \\
\text { and Soderquist, 2000), which should include the buyer/supplier's perspective regarding } \\
\text { contextual and strategic constraints (Kamann 2000; Kang et al., 2012); }\end{array}$ \\
\hline $\begin{array}{l}\text { VARIABLES- } \\
\text { RELATED ISSUES }\end{array}$ & $\begin{array}{l}\text { Correct operationalization of the selected variables (Ramsay 1996) and the related } \\
\text { measurement and weighting (Olsen and Ellram, 1997); }\end{array}$ \\
\hline $\begin{array}{l}\text { METHODOLOGICAL } \\
\text { ISSUES }\end{array}$ & $\begin{array}{l}\text { Sound methodology for the item positioning, i.e. classifying goods-services and/or B- } \\
\text { S relationships (Gelderman and Van Weele, 2002; Rezaei and Ortt, 2013a; b); }\end{array}$ \\
\hline $\begin{array}{l}\text { SUITABILITY } \\
\text { ISSUES }\end{array}$ & $\begin{array}{l}\text { Effective integration of complementary information for checking validity and for } \\
\text { synthesizing suitable recommendations (Ritter, 2000; Dubois and Pedersen, 2002; } \\
\text { Hesping and Schiele, 2016). }\end{array}$ \\
\hline
\end{tabular}

The following section expounds the development of the DSS model. 


\section{Decision Support System modeling}

This section explains the development of the FST-based DSS model. Section 3.1 briefly describes the FST and points out its suitability for our research purposes. Section 3.2 presents the overall architecture of the DSS we propose. Section 3.3 explains the decision-making logic, including the fuzzy processing of inputs and outputs and the aggregation procedure. Section 3.4 details the inputs and outputs of the model, while section 3.5 provides the used control variables. Thus, the main adopted dimensions, variables, and measures are analyzed.

\subsection{Fuzzy Set Theory}

FST can handle many real-world problems in different areas of decision science - e.g. technology selection, supplier selection, site selection, performance evaluation, and risk assessment - because it can lead to rational decisions based on imperfect information. Details on the foundation and subsequent evolution of the methodology are available in Zimmermann (2013). FST has been applied in the field of management and economics, where decision makers usually must deal with imperfect knowledge and vague factors. For a detailed review in the supplier selection domain, see Chai et al. (2013).

FST is based on the Fuzzy logic - a form of logic in which each variable is characterized by a truth value expressed by a real number ranging between 0 and 1 . This truth value is the grade of membership of a variable to a corresponding class and it is expressed through a membership function ( $\mathrm{mf}$ ). In other words, the values between 0 and 1 expound how much the degree of membership of the variable is true (1) or false (0). FST is often used in DSSs to deal with the aggregation of different variables (e.g. linguistic variables vs numerical indicators, objective performance indexes vs subjective judgment) and to reproduce approximate, knowledge-based, not-compensatory reasoning, e.g. through the Fuzzy Inference System (FIS). In particular, FST utilizes linguistic scales as a tool for expressing non-numeric values of the variables through rules and facts (e.g. the value of the membership function of the selected variable is rather low).

FIS design typically goes through the following steps:

1. Fuzzy set (linguistic variables) and membership function design. The process includes the definition of the universes and $\mathrm{mfs}$ for each variable. Triangular and trapezoidal $\mathrm{mfs}$ are commonly used because of their simplicity (Castillo and Melin, 2008). Linguistic and subjective variables are directly modeled drawing from the company expertise using appropriate membership functions.

2. Rule settings. The fuzzy rule base is the heart of a FIS and consists of a set of fuzzy IF-THEN rules to represent human knowledge or to reproduce other decision logics. The DSS tool must be effective (reasonable) and efficient (too many rules can result in unnecessary complexity). The following possibilities are available and can also be combined: (i) a normalized or standard rulebase; (ii) experts' experience and intuition; (iii) a fuzzy model of the process; and (iv) learning 
type controllers. In many managerial decision models, the knowledge base is elicited from the experience and intuition of experts through the analysis of actions, procedures, and cases (Aloini et al., 2010). In this methodology, the fuzzy-rule-based approach contributes by making practitioners discuss their priorities and by clarifying preferences regarding decision criteria, coping with the fuzziness that is unavoidable in real contexts.

3. Validation and Sensitivity Analysis. It includes case-based validation and the analysis of the output reliability to control input variation.

Regarding PPMs' implementation, FST could solve subjectivity and uncertainty issues in measuring and weighting the input variables and in positioning the items in the purchasing matrices. In particular, the fuzzy logic can mitigate the arbitrariness in the thresholds' definition and the compensatory logic in items/suppliers positioning. Also, it can facilitate the interpretation of borderline items/suppliers (see Table 2).

Table 2. PPM implementation and FST

\begin{tabular}{|c|c|c|}
\hline & \multicolumn{2}{|c|}{ FUZZY LOGIC application } \\
\hline PPM weakness & $\begin{array}{l}\text { Fuzzy modeling of dimensions, } \\
\text { variables and measures (fuzzy } \\
\text { sets definition) }\end{array}$ & $\begin{array}{l}\text { Fuzzy inference (inferential rules } \\
\text { definition) and positioning }\end{array}$ \\
\hline $\begin{array}{l}\text { Measurement and } \\
\text { weighting of input } \\
\text { variables }\end{array}$ & $\begin{array}{l}\text { - } \text { Multiple inputs; } \\
\text { - Subjective values; } \\
\text { - Uncertainty in quantitative data; } \\
\text { - } \quad \text { Subjective judgments (weights). }\end{array}$ & \\
\hline $\begin{array}{l}\text { Robust positioning of } \\
\text { items/suppliers in the } \\
\text { matrices }\end{array}$ & & $\begin{array}{l}\text { Arbitrariness in high-low } \\
\text { thresholds definition; } \\
\text { - Compensative logic in } \\
\text { items/suppliers positioning; } \\
\text { - Borderline items/suppliers' } \\
\text { interpretation; } \\
\text { - Approximate, knowledge-based } \\
\text { reasoning. }\end{array}$ \\
\hline
\end{tabular}

\subsection{DSS architecture and decision logic}

The DSS works through two main stages (Figure 1). First, it implements traditional PPMs, leveraging the methodological support of FST. Second, it focuses on the integration of additional information in the decision process to refine preliminary directions and test their suitability. Additional details on the methodology (stages, steps, inputs, outputs, tools and technical concerns) are presented in Table A1 in Appendix A. 


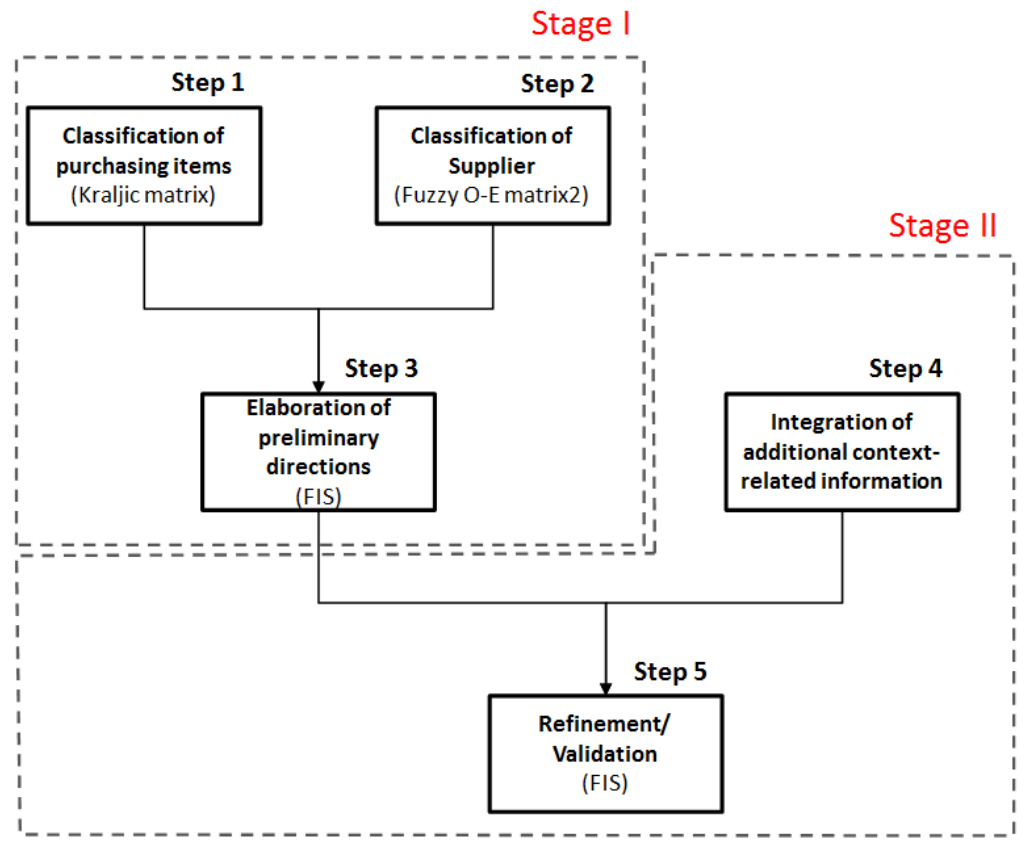

Figure 1. The two-stage, five-step decision logic

In stage 1, the model combines the output from the analysis of purchasing items, conducted through the Kraljic's (1983) matrix (step 1), with the outcomes from the classification of the B-S relationships, conducted through a fuzzy implementation of the O-E matrix 2 (step 2), to elaborate the preliminary directions/recommendations (step 3). In stage 1, the following activities are needed:

(a) Choice of variables and measures operationalizing the main dimensions of Kraljic and O-E matrices;

(b) Fuzzy modeling of the O-E model dimensions, variables and measures;

(c) Assessment of the relative importance of variables and measures in the aggregation process;

(d) Definition of the DSS design and setting through the FIS rules;

(e) Processing of outputs to define preliminary directions.

In stage 2, the model enriches the information gathered and processed in stage 1 with specific company policies (e.g., location of suppliers: local vs. global), purchasing item features (e.g., life cycle), and other context-related information on the purchasing situation (e.g., relative contractual power between Buyer and Supplier, cross-supply level, level of shared investments on the suppliers/buyer side). This provides a more effective and systematic validation of the outputs and of the refined recommendations based on company specific contingencies. In step 4, the new variables of analysis are measured while, in step 5 , preliminary outputs are refined accordingly by a fuzzy contingent validation, and feasible directions/recommendations are developed.

In detail, steps 4 and 5 involve: 
(a) the choice of additional information to be embedded into the model;

(b) fuzzy modeling of the additional dimensions, variables and measures;

(c) DSS design and setting by defining the FIS rules;

(d) refinement of preliminary outputs to draw feasible directions.

\subsection{Input-output modelling, item positioning, and refinement of outcoming directions}

We adopted fuzzy variables to set up the input data needed to fill the O-E matrix and to structure the related outputs. Fuzzy linguistic variables are used to codify the experts' judgments for all the investigated factors related to the two main O-E dimensions. Judgments are then aggregated (Figure 2) into a fuzzy index - one for each main matrix dimension - using the Fuzzy Weighted Average (WA) (Dong and Wong, 1987; Liou and Wang, 1992).

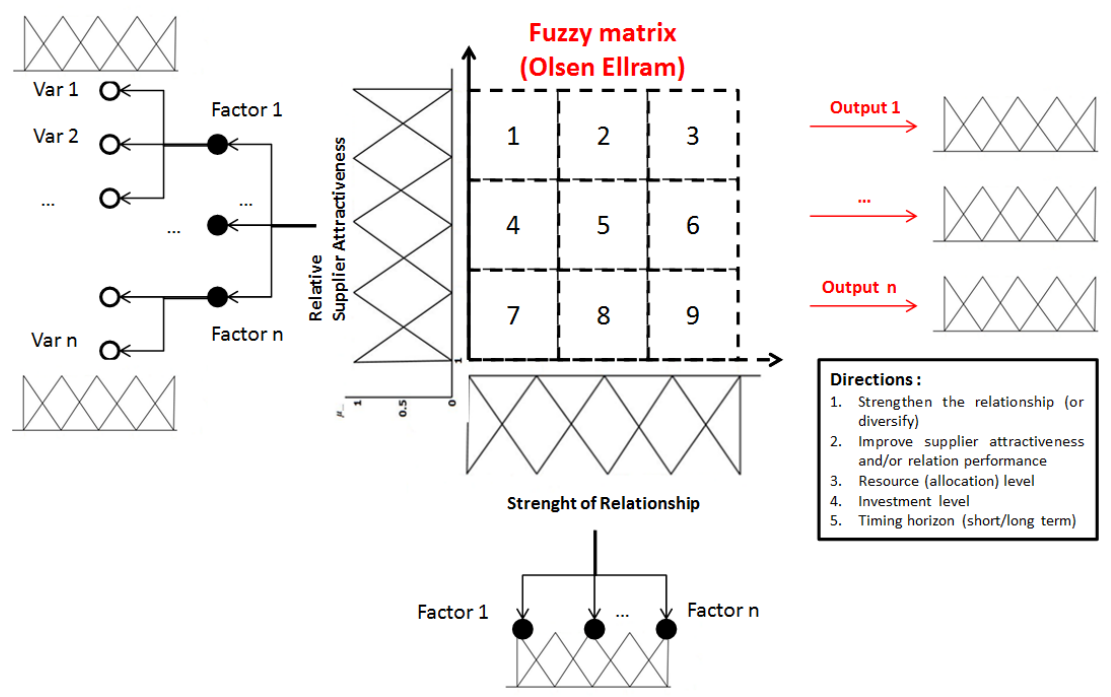

Figure 2. The fuzzy O-E matrix

This allows to assign a supplier to more than one individual quadrant (Figure 2) in the matrix, according to a different association degree and to a fuzzy borderline, making the classification more flexible and less restrictive. At this stage of the decision process, information on the purchasing situation (provided by Kraljic portfolio analysis) is added and included within the FIS to define the preliminary directions. Resulting recommendations are re-evaluated in a second step to validate their suitability and feasibility through a similar logic. The FST is used again in this last stage to characterize the preliminary and final model outputs. Any additional information included at this point and the overall decision logic are also characterized.

\subsection{Primary input and output specification}

Inputs. For each matrix, two macro-dimensions are considered: Profit (Strategic Importance of the Purchase) and Supply Risk (Difficulty in Managing the Purchasing Situation). Several factors and subfactors are selected to provide a complete measurement scale. In this way, purchasing items are 
classified as Bottleneck, Strategic, Leverage, and Not-Critical. Based on Supplier Attractiveness and Relationship Strength, as in the Olsen and Ellram matrix 2, B-S relationships are also analyzed.

Outputs. The model presents an output structure, which is more analytical (multi-input/multi-output model) when compared to more traditional approaches, to offer better precision and an easier interpretation of the outcomes. Output variables (Table 3) are drawn and refined according to the main directions provided by Kraljic (1983), Olsen and Ellram (1997), and by the subsequent criticisms (Kamann 2000; Nellore and Soderquist, 2000; Dubois and Pedersen, 2002). Hence, they include information on both strategic directions and macro actions to be implemented.

Table 3. O-E matrix outputs (adapted from Olsen and Ellram, 1997)

\begin{tabular}{l} 
O-E directions \\
\hline 1. Strengthen the relationship (or diversify); \\
2. Improve supplier attractiveness and/or relation performance; \\
3. Resource (allocation) level; \\
4. Investment level; \\
5. Timing horizon (short/long term). \\
\hline
\end{tabular}

\subsection{Additional information}

To guarantee viability, the resulting actions need to be evaluated in the light of some critical, contextrelated information, mainly related to the company's existing constraints (budget, policies, and other limitations of the supply base) or to other influencing factors. This is particularly true when PPMs are used for steering the purchasing strategies at a business unit level, since they usually have to be aligned with the corporate directives.

The selection of the information depends on the company's specific context and priorities. Two classes of information are suggested here:

1. Corporate constraints - mainly budget and uniformity constraints (i.e. standardization and homogeneity in the supply process). These factors may limit both investments (capital budget decisions) and other factors more related to the supplier selection process (the type of B-S relation, information exchange, integration level). Also, they can impact on purchasing policies (sustainability, ethic, local/global, multi/single sourcing policies).

2. Context-related factors that might limit appropriateness and feasibility of the recommendations derived from stage 1 (see Figure 1): product life cycle stage, level of current/shared investments (i.e. technology, specific assets, switching costs), company resources/assets currently allocated to the B-S relation, company's network position, and level of cross supply.

Although it could be argued that some of these factors or similar ones have already been included within O-E sub-dimensions, the methodology we propose allows to consider the variables separately and, consequently, it avoids any compensatory phenomenon. Also, the modular architecture enables higher model adaptability. 
The drivers we selected for the portfolio analysis are reported and analyzed in Table 4.

Table 4. Additional information

\begin{tabular}{|c|c|c|}
\hline & $\begin{array}{l}\text { Additional } \\
\text { information }\end{array}$ & Description \\
\hline \multirow{8}{*}{ 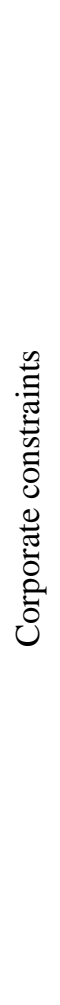 } & \multirow{2}{*}{$\begin{array}{l}\text { Budget } \\
\text { constraints }\end{array}$} & Budget (as company dimension) \\
\hline & & $\begin{array}{l}\text { The available budget can affect suitability of any suggested direction or action plan due to the } \\
\text { actual availability of financial resources. }\end{array}$ \\
\hline & \multirow{6}{*}{$\begin{array}{l}\text { Uniformity } \\
\text { constraints }\end{array}$} & Purchasing localization policy (Market dimension) \\
\hline & & $\begin{array}{l}\text { Localization policy can deeply influence the suitability of advanced recommendations. A } \\
\text { company may choose or be forced to prefer local partner to global ones to compete in specific } \\
\text { countries. For instance, a domestic supply market may not be sufficient to pursuit low-cost and } \\
\text { high-quality product strategies, or to find suppliers with adequate technological capabilities } \\
\text { (Wagner, 2004). Despite the ever-increasing potential for international/global sourcing, } \\
\text { scholars and managers should not underestimate the role of markets within their own continent } \\
\text { when analyzing their current purchasing (Karjalainen and Salmi, 2013). }\end{array}$ \\
\hline & & Single-vs Multi-sourcing \\
\hline & & $\begin{array}{l}\text { Choosing single-sourcing rather than multi-sourcing can affect some of the principal output } \\
\text { dimensions, such as strength of the relationship, diversification, desirable performance. } \\
\text { Several authors analyzed factors associated with both single and multiple sourcing decisions to } \\
\text { formulate sourcing strategies that are consistent with their quality strategies and other company } \\
\text { policies (Emalgraby, 2000; Berger and Zeng, 2006; Burke et al., 2007). }\end{array}$ \\
\hline & & Sustainability/Ethic or other company purchasing policies \\
\hline & & $\begin{array}{l}\text { Company policies should be analyzed for aligning the purchasing strategy with the overall } \\
\text { strategy and eventually with the corporate directions. For instance, sustainability (Pagel et al., } \\
\text { 2010), green purchasing, and social responsibility (Gallear et al., 2012) can strongly influence } \\
\text { the supply choices and the governance of B-S relationships. Ethical and environmental } \\
\text { awareness within the firm does increase the likelihood of closer relationship development with } \\
\text { suppliers through supply chain partnerships. }\end{array}$ \\
\hline \multirow{5}{*}{ 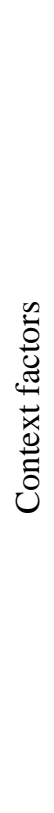 } & & The product life cycle (as a product dimension) \\
\hline & $\begin{array}{c}\text { Product Life } \\
\text { Cycle (PLC) stage }\end{array}$ & $\begin{array}{l}\text { B-S relationships' objectives, desirable performance, risk, and available resources change } \\
\text { according to the different PLC stages (Hayes and Wheelwright, 1979). Consequently, supply } \\
\text { chain strategies must be dynamically matched to maximize competitiveness (Aitken et al., } \\
\text { 2003; Birou et al., 1997). Thus, an effective decision model should take into account this factor } \\
\text { to provide suitable recommendations. }\end{array}$ \\
\hline & \multirow{3}{*}{$\begin{array}{l}\text { Concurrent/shared } \\
\text { investments }\end{array}$} & $\begin{array}{l}\text { Concurrent/shared investments express the dependence rate between buyer and supplier. This } \\
\text { rate is operationalized by the level of shared investment and sometimes by the volume of cross } \\
\text { supply (a supplier which offer multiple components), as a measure of the relative contractual } \\
\text { power. It is widely established that the existence of idiosyncratic investments can influence the } \\
\text { choice of governance structure, coordination mechanisms, contractual constraints and, more in } \\
\text { general, the type of B-S relationship (Bensaou, 1999; Bensaou and Anderson, 1999). }\end{array}$ \\
\hline & & $\begin{array}{l}\text { Cox (2001) outlines how the power perspective can enhance effective procurement and supply } \\
\text { management depending on several power attributes that may be available to buyers and } \\
\text { suppliers, e.g. number of buyers/suppliers, market share, relative revenue dependence, } \\
\text { switching costs, searching costs, and information asymmetry. }\end{array}$ \\
\hline & & $\begin{array}{l}\text { Power and interdependence are fundamental in managing B-S relationships (Olsen and Ellram, } \\
\text { 1997; Caniels and Gelderman, 2007). They are already considered at different stages of the } \\
\text { model assessment in both Kraljic (1983) and Olsen-Ellram (1997). Nevertheless, in our opinion, } \\
\text { they should be considered again in validating the proposed purchasing directions or } \\
\text { refinements. }\end{array}$ \\
\hline
\end{tabular}

\section{Methodology}


Given the nature of our research objectives, expressed through how research questions ( $c f$. section 1), the case study methodology was suitable (Yin, 2013). The objective of the case study was to highlight the practical applicability of the DSS and to validate it in a real-life context. The selected case was a branch of a power electronics multinational company that needs to revise its purchasing strategy to align it with the corporate policies and directions and to systematize, support, and automate the purchasing decision process to assure effectiveness and efficiency.

Hence, Section 4.1 describes the context of the case, while Section 4.2 specifies the data collection and the model setting.

\subsection{The case context}

The company serves a massive market consisting of Original Equipment Manufacturer (OEM) companies, Distributors, and also Engineering, Procurement, and Construction (EPC) contractors or sub-contractors installing power and automation technologies. Over the last decade, the company has undergone an impressive expansion due to the core business growth and the penetration of new markets, including the entry into new application fields fostered by several acquisitions. This has also led to an increase in both the procurement and the supplier base. Therefore, the Global Realignment project has been launched to homogenize the information and the procedural structures of the new plants with the existing corporate ones. This project also involves the re-organization of Sourcing and Purchasing.

The company procures a large variety and quantity of products, works, and services (see Table 5). It mostly follows a multi-sourcing strategy (or at least dual-sourcing) to minimize the supply risk. However, single-sourcing experiences are increasing after the expansion due to both a desire to concentrate the supply's demand by exploiting a higher contractual power and the increasing development of partnerships with the most strategic suppliers for new product development in the new application fields.

Thus, the organization follows different purchasing actions and methods, from spot purchasing to competitive bidding and requests for quotation, including rate contracts, umbrella agreements and agreements through negotiation. Statistics regarding the purchasing items, their class, and suppliers according to Kraljic's classification are shown in Tables 5 and 6.

Table 5. Purchased items and their classes

\begin{tabular}{cl}
\hline Class (\% of the purchasing volume) & \multicolumn{1}{c}{ Class Type } \\
\hline & Alarm; connector; heat management; insulator; magnetics; \\
Electro-mechanical (31\%) & terminal material; printed circuit board; relay; switch; wire; \\
& Magnetics material; passive; semiconductor; fixed resistors; \\
Electronics (30\%) & Manual; \\
Literature (3\%) & Bus bar; enclosure; fastener; hardware; Heat Management; \\
Mechanics (35\%) & Label; Metal; Packaging; \\
MFG $(1 \%)$ & Accessory; chemicals; batteries; lighting; miscellaneous. \\
\hline
\end{tabular}


Table 6. Classification of the suppliers according to the Kraljic's classes

\begin{tabular}{cc}
\hline Kraljic class & Number of suppliers \\
\hline Strategic & 55 \\
Bottleneck & 15 \\
Leverage & 39 \\
Noncritical & 99 \\
\hline Total & 208 \\
\hline
\end{tabular}

\subsection{Data collection and model settings}

A group of experts belonging to the company was selected to gather the needed purchasing and context information, and two academic experts were appointed to manage the process (Table 7).

Table 7. Interviewed subjects

\begin{tabular}{cllc}
\hline ID & \multicolumn{1}{c}{ Position } & $\begin{array}{c}\text { Time with company } \\
\text { (years) }\end{array}$ & $\begin{array}{c}\text { Number of } \\
\text { similar project }\end{array}$ \\
\hline 1 & Senior Sourcing Manager & More than 10 years & 2 \\
2 & Sourcing Manager & 5 year & 1 \\
3 & Buyer & More than 10 years & 2 \\
4 & Buyer & 5 years & 1 \\
5 & Buyer & 6 years & 1 \\
6 & Buyer & Less than 1 year & 0 \\
7 & Logistics Manager & 5 years & 0 \\
8 & Quality Manager & 6 years & 1 \\
9 & Expeditor & More than 10 years & 2 \\
10 & Expeditor & Less than 1 year & 0 \\
\hline
\end{tabular}

For fostering the information collection, we developed two questionnaires: one for conducting semistructured interviews and another one for conducting focus groups. The first questionnaire focused on evaluating the suppliers' attractiveness, while the second one was used to identify the performance scores of the suppliers in accordance with the Kraljic and O-E's dimensions (Tables A2 and A3 in Appendix A). Respondents were asked to indicate the degree to which they agreed with each statement on a 5-point linguistic scale (Table 8).

Table 8. Membership functions (input-output)

\begin{tabular}{ccc}
\hline & Linguistic scale & Triangular fuzzy number \\
\hline mf1 & Very low & {$[1,1,2]$} \\
mf2 & Low & {$[1,2,3]$} \\
mf3 & Medium & {$[2,3,4]$} \\
mf4 & High & {$[3,4,5]$} \\
mf5 & Very high & {$[4,5,5]$} \\
\hline
\end{tabular}


A Delphi-based process was also adopted to achieve convergence of the experts' judgments, since it is appropriate when researchers need to elicit knowledge from experts with different perspectives and/or complementary information (Brown, 1968). Thus, preliminary judgments about the related suppliers were formulated by each participant for the related suppliers, and the process was reviewed by an internal supervisor - generally the Sourcing or Senior Sourcing Manager. The process was reiterated until consensus, and Table 9 shows the output. A similar procedure was adopted to define the aggregation weight for the sub-variables.

Table 9. O-E inputs for items' suppliers

\begin{tabular}{lccc}
\hline \multicolumn{1}{c}{ Parameters } & Supplier A & Supplier B & Supplier C \\
\hline Volume or monetary value of purchases & $(4,5,5)^{*}$ & $(3,4,5)$ & $(1,1,2)$ \\
Importance of the buyer to the supplier & $(2,3,4)$ & $(1,2,3)$ & $(1,1,2)$ \\
Exit-Switching costs & $(3,4,5)$ & $(1,2,3)$ & $(1,1,2)$ \\
Level and number of personal contacts & $(4,5,5)$ & $(4,5,5)$ & $(1,1,2)$ \\
Duration of the exchange relationship & $(4,5,5)$ & $(1,1,2)$ & $(1,2,3)$ \\
Cooperation in development & $(3,4,5)$ & $(3,4,5)$ & $(2,3,4)$ \\
Technical cooperation & $(3,4,5)$ & $(3,4,5)$ & $(2,3,4)$ \\
Integration on management & $(3,4,5)$ & $(3,4,5)$ & $(1,2,3)$ \\
Reliability & $(3,4,5)$ & $(3,4,5)$ & $(3,4,5)$ \\
Flexibility & $(3,4,5)$ & $(3,4,5)$ & $(4,5,5)$ \\
Speed & $(3,4,5)$ & $(2,3,4)$ & $(3,4,5)$ \\
Quality & $(4,5,5)$ & $(3,4,5)$ & $(4,5,5)$ \\
Price & $(3,4,5)$ & $(2,3,4)$ & $(2,3,4)$ \\
Ability to cope with changes in Technology & $(4,5,5)$ & $(4,5,5)$ & $(1,2,3)$ \\
Supplier's design capability & $(3,4,5)$ & $(3,4,5)$ & $(1,2,3)$ \\
Supplier's current and future technological capability & $(4,5,5)$ & $(4,5,5)$ & $(1,2,3)$ \\
Financial stability & $(3,4,5)$ & $(3,4,5)$ & $(3,4,5)$ \\
Supplier's scale and experience & $(4,5,5)$ & $(3,4,5)$ & $(1,2,3)$ \\
General risk and uncertainty in dealing with the supplier (stop) & $(4,5,5)$ & $(4,5,5)$ & $(4,5,5)$ \\
Internal and external integration with the supplier & $(3,4,5)$ & $(3,4,5)$ & $(2,3,4)$ \\
\hline
\end{tabular}

* (See table 8 for the corresponding linguistic variables)

Company experts were also involved in the DSS assessment, concerning the definition of FIS rules (Figure 3) and the final model validation. 


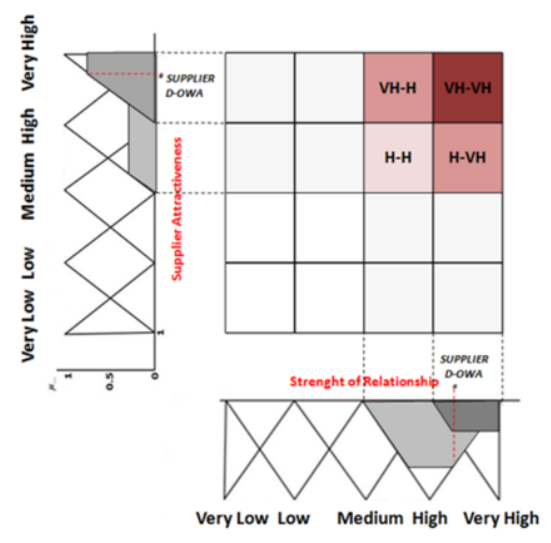

Decision rules are expressed according to the

following statements:

IF

the Purchasing Item IS a (Kraljic class)

AND

Supplier Attractiveness IS (level)

AND

Strength of the Relationship IS (level)

THEN

Strengthen the Relation IS (level)

Improve Supplier Attractiveness IS (level)

Level of Investment IS (level)

Level of Resource IS (level)

Timing horizon of relation IS (level)

Figure 3. Positioning in the fuzzy O-E matrix

To implement the fuzzy model, several semi-structured interviews were conducted (Qu and Dumat, 2011). The semi-structured interviews allowed identifying the specificity of the individual experts without limiting the interview to a set of predetermined responses, while the Delphi-based process provided uniformity in the investigation. Specifically, the open-ended questionnaire included a set of questions to:

- Discuss the dataset and define the variable labels (linguistic values);

- Determine the fuzzy range of each value label, when objective historical data were not available;

- Express the fuzzy IF-THEN rules.

Once all the screening heuristics were identified, they were transformed into proper fuzzy IF-THEN rules to be implemented into the FIS engine, which uses the Mamdani inference method.

Finally, managers and senior buyers from the company's implementation team were involved in testing and validating the fuzzy system. The framework and the methodology were validated on three dimensions (inputs-positioning-final outcomes). Lastly, a sensitivity analysis was carried out on the weights adopted for factor aggregation to test the robustness of the model in positioning the suppliers. The results did not show any significant variation in the final placement.

To clarify how the system works and which valuable information was gathered, the next section reports and discusses the results from the case about one Kraljic's class purchasing items. The focus on a particular class is just for the sake of simplicity and clarity and does not undermine the significance of the results, which are far more extensive.

\section{Case results and discussion}

Following the Kraljic's classification, the chosen items belong to the Bottleneck class, which is characterized by a low purchase importance (profit impact) and a high complexity in managing the B$S$ relationships (also supply risk). 
Concerning the purchase importance - the first Kraljic's dimension - these items are fundamental components of any electronic assembly but, at the same time, their impact on both the economic value of the final product and its quality is quite low. This condition, which determines the low score assigned by experts to the overall profit impact, is probably due to the consolidated high-quality level of such components on the global market. Yet, these items are quite complex since they are characterized by a high rate of innovation: supplier-driven improvements in technology are frequent and new item releases often occur. Moreover, co-design activities may also take place to specifically customize the products. As for the B-S relationship, the sector is very capital-intensive, and the market is extremely concentrated. The few big suppliers are mostly located in Asia, and this strongly affects logistics costs and the related process performance. In this case, the availability of supply sources (i.e. the different suppliers) should be managed with higher priority. Traditionally, suitable approaches include overordering when the item is available, and looking for strategies to control vendors and deal with the related supply risks. As proposed by Kraljic (1983) and Gelderman and Van Weele (2003), two classes of actions or scenarios can be identified:

- A dynamic scenario, in which decision makers can try to move the purchasing code to another position in the matrix, mostly by diversifying the supply base or simplifying the product (which is very difficult for the selected items). Both the alternatives require the availability of a budget to invest in design activities or market research (financial/economic feasibility). Moreover, they need specific evaluations about the feasibility from both a technical point of view (technical feasibility) and a managerial perspective (related to the relative B-S contractual power, and to the existing or desirable relationships with the suppliers, as highlighted by the O-E analysis too).

- A static scenario, where decision makers accept the dependence and provide contingency plans, according to a risk management approach. As the price is little relevant, they might leverage factors that influence the relative contractual power and/or the B-S relationships: e.g. long- and medium-term procurement plans, new consignment/delivery systems, long-term agreements, inclusion of quality and logistic performance evaluations in the supply contracts, solutions to ensure the supply and insure against the risk, e.g. adoption of consignment and/or extra stocks (if necessary).

In the following sections (5.1 and 5.2), we describe the two decision stages of the DSS and the related subsequent actions. Stage 1 exploits both the Kraljic's matrix and a fuzzy implementation of the O-E matrix 2 ( $c f$. Section 3.2). Thus, it elaborates fuzzy-enabled, objective purchasing directions that cannot be generated through the classical PPM approaches only. In addition, stage 2 refines and enriches such directions with factors that are critical in depicting purchasing strategies (cf. Section 3.5) but that are completely overlooked by the Kraljic and O-E's matrices.

\subsection{DSS Stage 1: assessment of preliminary directions}


In step 1, the DSS integrates the implications related to the resulting Kraljic class (the items were classified as Bottleneck) with results from the fuzzy O-E matrix 2. The three suppliers (A, B, C) were evaluated by using the fuzzy linguistic variables selecting a representative and significant subset of measurement variables (see Appendix A). Outputs modelling the key Strategic Purchasing directions were assessed by the FIS (Figure 4). Table A4 in Appendix A reports the FIS rules for the Bottleneck class. A total of 100 rules ( $4 \times 5 \times 5)$ were identified and implemented at this stage of the DSS decision block.
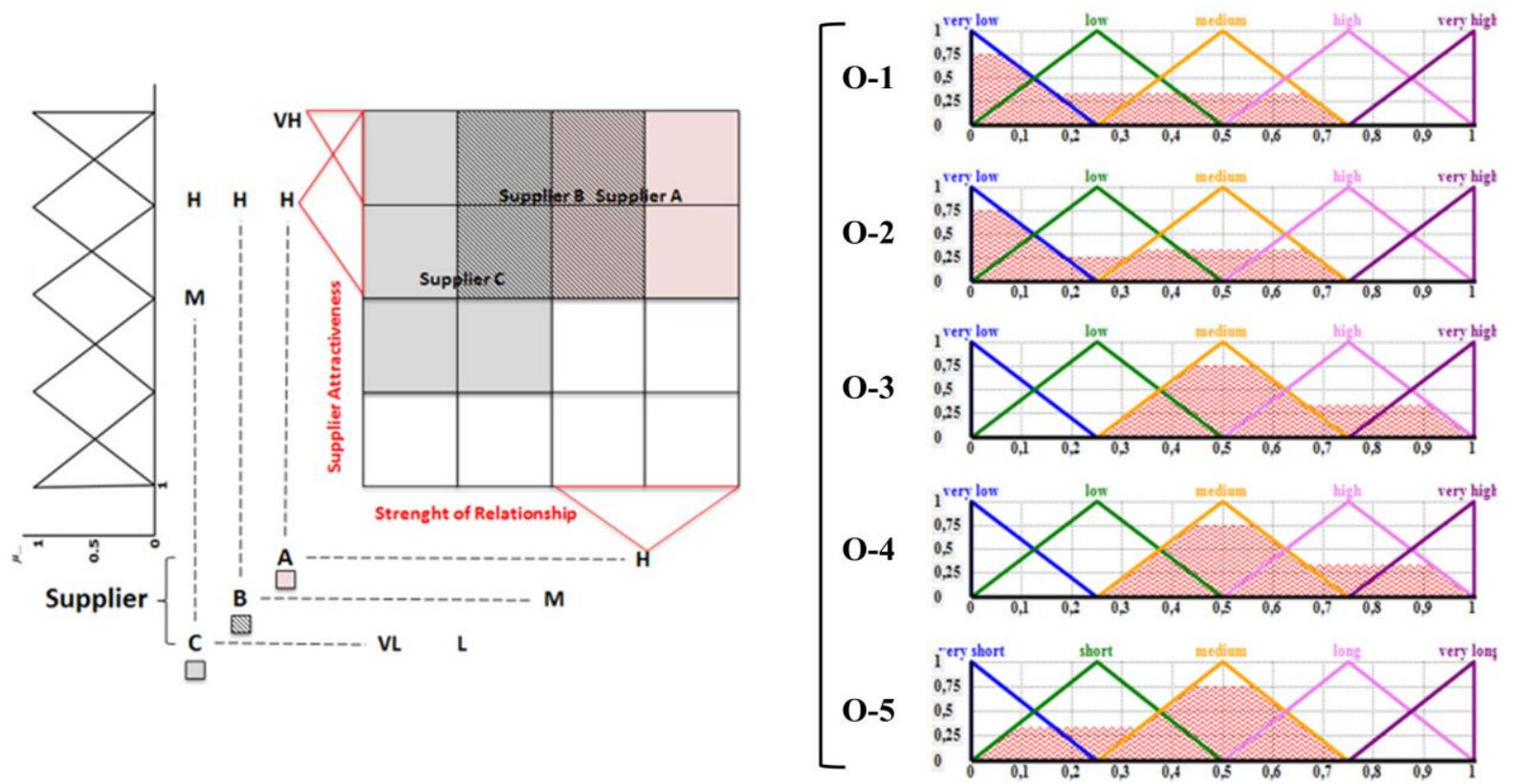

Figure 4. Positioning on the fuzzy O-E matrix and output statement for Supplier A (VL: VeryLow; L: Low; M: Medium; H: High; VH: VeryHigh)

$\mathrm{x}$-axes represent the domain of the linguistic variables $\mathrm{O}-1, \mathrm{O}-2, \mathrm{O}-3, \mathrm{O}-4$ and $\mathrm{O}-5$ $\mathrm{y}$-axes represent the membership degree

Table 10. Table of outputs (item - decision stage 1)

\begin{tabular}{lllll}
\hline \multicolumn{1}{c}{ Outputs } & \multicolumn{1}{c}{ Supplier A } & \multicolumn{1}{c}{ Supplier B } & \multicolumn{1}{c}{ Supplier C } \\
\hline 1 & Strengthen the relation & VL-M* $(0.316)^{* *}$ & L-H $(0.5)$ & L-H $(0.5)$ \\
2 & Improve Supplier Attractiveness & VL-M $(0.316)$ & VL-M $(0.316)$ & L-M $(0.375)$ \\
3 & Desirable resource level & M $(0.5)$ & M-H $(0.625)$ & M-H $(0.625)$ \\
4 & Target investment level & M $(0.5)$ & M-H $(0.625)$ & M-H $(0.625)$ \\
5 & Timing horizon & M $(0.5)$ & L-M $(0.375)$ & L-M $(0.375)$ \\
\hline
\end{tabular}

* VeryLow [VL], Low [L], Medium [M], High [H], VeryHigh [VH]

$* *$ (center of gravity of fuzzy $\mathrm{mf}$ )

By interpreting the values reported in Table 10 (first-stage outputs), the following directions concerning the three suppliers emerge.

First, Output 1 shows that actions should be planned to reinforce (moderate strength) the relation with Suppliers B and C. Conversely, Supplier A is already strongly involved in the company and, thus, a 
minor emphasis on this factor emerges. Yet, the intense relationship with Supplier A, which is essential to ensure the continuity of supply, needs to be monitored because of the asymmetry in the contractual power.

Output 2 proposes to improve the level of attractiveness of Supplier B and Supplier C. This entails concentrating internal resources and new investments (Outputs 3 and 4, from moderate to high) on Suppliers B and C. Thus, the suggested direction in the mid-term is to diversify the supply base or rebalance the relationship with Supplier A. To achieve these future objectives, the company should quickly (in the short/mid-term) increase the internal resources allocated to Suppliers B and C (new investments, information sharing and new logistic agreements). Obviously, it is also desirable to plan in the mid-long term to identify new potential suppliers or implement a product simplification strategy to reduce the supply risk. In fact, new potential suppliers could rapidly appear in the vibrant Asian markets, and then product standardization strategies could be pursued in the mid-long term when products move forward along their life cycle.

\subsection{DSS Stage 2: refinement and validation of preliminary directions}

Although the preliminary directions stemming from the first decision stage are rather analytical and complete, they are still far from any immediate application. As discussed in Section 3, they need to be validated in the light of additional factors, which can either limit or influence the feasibility in the specific context. For instance, the higher the level of internal resources already allocated to the B-S relation, the higher the moderation and caution in modifying the current relation without a strong risk management orientation. This prudence is usually advisable for high levels of B-S specific/shared investments too, and also for the level of cross supply volume (Bensaou, 1999; Cox, 2001). Furthermore, as the literature suggests (e.g. Hayes and Wheelwright, 1979; Birou et al., 1997; Aitken et al., 2003; Rink et al., 2003), the PLC stage of both the final products and the purchasing items is expected to influence the company's opportunity to invest new resources in a specific supplier and, more generally, in the overall Supply Chain Strategy: the more mature the PLC stage, the lower the appeal for new investments.

In addition, the existence of global corporate purchasing policies (localization, single- vs multisourcing, ethic/sustainability) may affect the suitability of a stronger relation with suppliers. Corporate orientation towards multi-sourcing might moderate the proposal to strengthen the link with a single supplier (Berger, 2006; Burke et al., 2007; Burke et al., 2008). In the same way, ethic/sustainability policies can reduce the opportunity to build relations with unsuitable suppliers (Pagel et al., 2010; Gallear et al., 2012). However, budget constraints are very critical to all the actions requiring new investments or resources. Hence, all these conditions imply that the three above-mentioned groups of control variables can act as moderators in the decision model since they strongly influence the suitability of the final directions. 
As a consequence, in step 2, the DSS analyzed the suitability of preliminary outcomes according to specific company constraints and other context-related factors. The variables were modelled by a fuzzy linguistic scale with triangular membership functions (Table 11). This information is useful to refine and check the validity of the preliminary directions (technical, economical, and corporate compatibility) and, if possible, to define how managers should carry out and pursue each action. The outputs were inferred by the FIS considering the score assigned to the selected control variables by the implementation teams (Table 12).

Table 11. Membership functions (controls)

\begin{tabular}{ccc}
\hline mfs & Linguistic scale & Triangular fuzzy number \\
\hline $\mathrm{mf} 1$ & Low & {$[1,1,2]$} \\
$\mathrm{mf} 2$ & Medium & {$[1,2,3]$} \\
$\mathrm{mf} 3$ & High & {$[2,2,3]$} \\
\hline
\end{tabular}

Table 12. Values of the Control variables

\begin{tabular}{lccc}
\hline \multicolumn{1}{c}{ Control variables } & Supplier A & Supplier B & Supplier C \\
\hline Concurrent/shared investment level & $\mathrm{H}^{*}(0.5,1,1)^{* *}$ & $\mathrm{~L}(0,0,1)$ & $\mathrm{L}(0,0,0.5)$ \\
Currently allocated resource level & $\mathrm{H}(0.5,1,1)$ & $\mathrm{M}(0,0.5,1)$ & $\mathrm{L}(0,0,0.5)$ \\
Sustainability/ethic policy fit & $\mathrm{H}(0.5,1,1)$ & $\mathrm{M}(0,0.5,1)$ & $\mathrm{L}(0,0,0.5)$ \\
\hline \multicolumn{4}{c}{ * VeryLow [VL], Low $[$ L], Medium $[\mathrm{M}]$, High $[\mathrm{H}]$, VeryHigh $[\mathrm{VH}]$} \\
\\
\end{tabular}

At this stage of the DSS decision process, 135 rules for each output $(5 \times 3 \times 3 \times 3)$ were identified and implemented. To set the FIS, experts were asked to choose a relevant control variable for Bottleneck codes. The implementation team focused on a few relevant variables: uniformity constraints, level of concurrent/shared investments, and level of resource currently allocated in the B-S relationship. The reasons for selecting these variables are reported in Table A5 in Appendix A.

The outcoming refined directions suggest maintaining the relationship with Supplier A, which is still attractive for the company (Table 13). Unexpectedly, actions to be planned for the mid-term should continue to strengthen the relationship and invest in Supplier A to limit the supply risk. This is due to the high level of specific investments shared with the supplier and the considerable amount of internal resources already allocated to the relationship. In addition, the supplier fits well with the Sustainability and Ethic corporate policy, which is a strong uniformity requirement imposed to all the local Business Units. Finally, the high market growth rate for Renewable Energy products means that the supply capability available should not be reduced.

If, in the long term, the company needs to plan diversification strategies, e.g. leveraging an intensive screening of the market, in the mid-short term the efforts can be strictly aimed at maintaining supplier A and developing supplier B. Directions suggest strengthening the relationship with these suppliers 
moderately. Resources and investments can be focused on improving the suppliers' operational performance and their potential and capabilities for increasing their attractiveness in the short/mid-term. On the other hand, Supplier C seems to be the least attractive. Although preliminary results suggesting the need to strengthen the relationship, e.g. by planning new investments and allocating new resources, the inadequate fit with the uniformity constraints (mostly the Sustainability and Ethical corporate policy) strongly modified the suitability of this action. Even though the specific investments and the resources already allocated to the relation are still low, the refined directions highlight that the company should be very careful in strengthening a relation that may turn out to be risky. In fact, the supplier demonstrates a scarce operational performance and low potential in terms of technological and innovation capabilities. Thus, diverging from the preliminary directions, the refined results suggest discarding Supplier C very quickly.

Table 13. Refined outputs (item - decision stage 2)

\begin{tabular}{cccc}
\hline Outputs & Supplier A & Supplier B & Supplier C \\
\hline Strengthen the relationship & $\mathrm{H}^{*}(0.75)^{* *}$ & $\mathrm{M}(0.5)$ & $\mathrm{VL}(0.08)$ \\
Improve supplier attractiveness & $\mathrm{H}(0.75)$ & $\mathrm{L}-\mathrm{M}(0.342)$ & $\mathrm{VL}(0.095)$ \\
Desirable resource level & $\mathrm{H}(0.75)$ & $\mathrm{M}(0.5)$ & $\mathrm{L}(0.218)$ \\
Target investment level & $\mathrm{H}(0.75)$ & $\mathrm{M}(0.5)$ & $\mathrm{L}(0.218)$ \\
Timing horizon & $\mathrm{M}(0.5)$ & $\mathrm{L}-\mathrm{M}(0.375)$ & $\mathrm{VL}(0.095)$ \\
\hline
\end{tabular}

*VeryLow [VL], Low [L], Medium [M], High [H], VeryHigh [VH] ** (center of gravity of Fuzzy mf)

The above-discussed results show that our approach integrates the Kraljic and O-E's strategies and enriches them with several validity checks. Also, the final directions provided by the DSS model are in line with evidence and recommendations from Bensaou (1999) and Cox (2001). Their models analyze B-S relationships related to idiosyncratic investments and relative B-S power and illustrate objectives and priorities for an appropriate management. Hence, company's B-S relationships for the analyzed purchasing item can be classified into the Captive Buyer and the Strategic Partnership program, since the company market in the Renewable Energy sector is expanding, but it is still concentrated in one main area, so that at the same time numerous potential incumbents exist. The products are quite complex, and the implemented technology is globally mature, although customizations are frequent and specific innovations arise especially through B-S engineering interactions. Also, looking at the relative contractual power, the suppliers' characteristics (a few, big, consolidated suppliers) force the company to be strongly dependent (captive buyer). On the one hand, according to the market perspective and the product characteristics, the company would like to establish a Strategic Partnership with the suppliers. On the other hand, the suppliers' characteristics and the degree of dependence strongly limit this option. Thus, the company needs to manage the supply risk in the short term by maintaining the old link with Supplier A. Concurrently, it should start planning for the inclusion of Supplier B in the short/mid-term. 
Finally, in the long term, it should consider investing in new market opportunities, mainly through intensive screening of the supply market.

\section{Conclusion and further research}

To our best knowledge, this work is the first attempt to effectively integrate traditional purchasing portfolio approaches with additional strategic-oriented priorities and contextual constraints to provide managers with refined and suitable purchasing directions. Thus, it tries to overcome several major shortcomings in the literature, contributing on three levels: theoretical, methodological, and managerial (Table 14).

Table 14. Research contributions

\begin{tabular}{|c|c|}
\hline Scope & Contribution of the work \\
\hline \multirow{4}{*}{ THEORETICAL } & $\begin{array}{l}\text { Answers the need, highlighted by Lau et al. (2005), to expand the domain of knowledge-based DSSs } \\
\text { for procurement decision and to enhance their flexibility by considering additional factors (cf. } \\
\text { Modelling Issues and Suitability Issues in Table 1); }\end{array}$ \\
\hline & $\begin{array}{l}\text { Replies to the extreme simplification of classical PPMs by explicitly including strategic-oriented } \\
\text { priorities and contextual constraints in the evaluation (cf. Modelling Issues and Suitability Issues in } \\
\text { Table 1); }\end{array}$ \\
\hline & $\begin{array}{l}\text { Offers a comprehensive and systematic framework to assess the purchasing situation (cf. Suitability } \\
\text { Issues in Table 1); }\end{array}$ \\
\hline & $\begin{array}{l}\text { Suggests a novel structure of the PPMs' outputs for a more analytic characterization of strategic } \\
\text { directions ( } c \text { f. Suitability Issues in Table 1); }\end{array}$ \\
\hline \multirow{3}{*}{ METHODOLOGICAL } & $\begin{array}{l}\text { Exploits FST's support for input coding, knowledge elicitation, and output representation ( } c f \text {. } \\
\text { Variables-related Issues in Table 1); }\end{array}$ \\
\hline & $\begin{array}{l}\text { Limits arbitrariness and compensatory processes in item/supplier positioning (cf. Variables-related } \\
\text { Issues and Methodological Issues in Table 1); }\end{array}$ \\
\hline & $\begin{array}{l}\text { Offers a modular multi-input, multi-output model architecture (cf. Methodological Issues in Table } \\
\text { 1); }\end{array}$ \\
\hline \multirow{4}{*}{ MANAGERIAL } & $\begin{array}{l}\text { Leverages the purchasing-related knowledge base for supporting decision makers in integrating } \\
\text { different perspectives, enabling knowledge sharing and group decision processes (cf. Suitability } \\
\text { Issues in Table 1); }\end{array}$ \\
\hline & $\begin{array}{l}\text { Allows managers to check the feasibility of the outcoming PPMs' directions (cf. Suitability Issues } \\
\text { in Table 1); }\end{array}$ \\
\hline & $\begin{array}{l}\text { Guides managers to structure the fuzzy-based decision process from the input statement through the } \\
\text { knowledge elicitation, including the rules definition (cf. Methodological Issues and Suitability } \\
\text { Issues in Table 1); }\end{array}$ \\
\hline & Provides managers with easily interpretable outputs (cf. Suitability Issues in Table 1). \\
\hline
\end{tabular}

From a theoretical perspective, this manuscript points out that the procurement-related, multi-factor knowledge base, elicited from the purchasing experts and from the historical evaluations of the purchasing ratings through our fuzzy-based DSS model, can extend the capabilities of the decision makers in the management of the purchasing process ( $c f$. Lau et al., 2005). In addition, it broadens and integrates traditional PPMs, particularly Kraljic (1983) and Olsen and Ellram (1997), overcoming the major criticisms about the oversimplification of the decision logic and the neglecting of the complexity of B-S relationships and context-related implications. Furthermore, the work answers the calls from the literature to include additional information (e.g. overall business strategy, specific situations of supply 
markets, capacities and intentions of individual suppliers) for customizing the PPM decision approach to a firm's specific situation (Nellore and Soderquist, 2000; Gelderman and Van Weele, 2003).

Also, the paper provides a more comprehensive and systematic framework to assess and analyze the purchasing situation of items and B-S relationships and both interpretation and evaluation of the outcomes, considering additional information usually overlooked by traditional approaches. In addition, responding to the criticism by Dubois and Pedersen (2002), the proposed multi-output structure is a novel way of presenting the PPMs' outputs, offering managers a more analytical characterization of strategic directions and providing richer and more accurate information in the assessment and modulation of managerial actions.

The methodological contribution lies in the adoption of the FST to tackle arbitrariness and compensatory processes in item positioning. Most methods suggested in the literature are based on subjective judgments and macro-factor aggregations that sometimes lack analytical rigor and lead to erroneous outputs and interpretations (Rezaei and Ortt, 2013a, b). Hence, interpretation, deployment, and contextualization of final directions or action plans are neither systemic nor systematic because they depend on the evaluation of decision makers and are subject to the users' skills, competence, and culture.

Unlike traditional approaches, our DSS supports users in a systematic and more complete assessment of potential actions. Thus, the suggested approach - although more complex and time-consuming improves quality and reliability of purchasing managers' information, and of their judgments and decisions. The innovative characteristics of the method are:

- A more complete and flexible input structure, including the specification of company policies and other context-related information;

- A multi-input, multi-output architecture, with a more analytical output structure that leads to more complete outcoming information;

- A two-stage architecture of the decision model which is modular and confines the effects of contingencies to the second stage. This implies a more flexible use and re-parameterization of the model;

- Subjective data can be handled in a more effective, non-compensatory way;

- A more appropriate elicitation of knowledge and user experience.

From a knowledge management perspective, this manuscript provides an additional contribution. The DSS model it proposes can be framed as a knowledge elicitation tool, in line with Gavrilova and Andreeva (2012) and Shadbolt and Smart (2015). Thus, by drawing from both tacit and explicit knowledge, stemming from the involved experts and from the past purchasing performance evaluations respectively, the DSS model can enable the creation of actionable, purchasing-related insights. In so doing, it is consistent with the knowledge creation model by Nonaka and Toyama (2015), it supports 
knowledge transfer activities, and it confirms the role that knowledge management can play in improving the decision-making process ( $c f$. Courtney, 2001; Nemati et al, 2002).

The managerial implications of our methodology stem directly from the above-mentioned characteristics. In particular, by leveraging the purchasing-related knowledge base, extracting and valuing it in a deeper and more objective way, the Fuzzy DSS support users in:

- Providing managers with additional context variables (e.g. budget constraints, purchasing localization policies, and so on) to check the feasibility of the outcoming strategic direction;

- Structuring, systematizing, and codifying the decision process starting from the input statement through the knowledge elicitation (drawing on the literature evidence and managers' experience), including the definition of rules and the refinement/validation of suitable outputs;

- Integrating different decision-making perspectives, allowing knowledge sharing and group decision making processes by a flexible combination of FST and expert systems;

- Presenting outputs that are more analytical and that can be interpreted in an easier way.

The methodology and the related DSS are mainly used to support managers in complex purchasing situations where specific contingencies, linked to heavy environmental constraints or organizational structures, impact significantly on purchasing decisions $-e . g$. corporate policies and directives can substantially influence local purchasing choices at a Business Unit level. The suggested approach allows managers to systematically and objectively integrate these control/moderating variables within the decision logic of PPMs.

Yet, there are also various limitations in this approach. The results from the case study support the use and point out the importance and applicability of the methodology and of the DSSs, and they highlight the strength of the technique by refining preliminary outcoming directions into more suitable ones. However, this does not attempt any generalization. Moreover, although FST demonstrated effectiveness in coping with the criticalities of the extant PPMs, it is strongly dependent on the elicitation of knowledge from managers and experts.

Further enhancements should focus on a thorough validation of the methodology. Action Research might be a promising approach, since it can provide an effective and practical way of improving the development and testing of such a system. Supplementary analyses could also provide stronger evidence of the potential of purchasing portfolio approaches in managerial practice.

Overall, in our humble opinion, the presented approach moves towards a more systematic and flexible method for drawing strategic purchasing directions. Although the standardization and automation of portfolio analysis is neither possible nor recommended, critical thinking is needed, and a more complete and precise assessment of the variables involved in the purchasing analysis would certainly facilitate and enhance managers' work.

\section{References}


Aitken, J., Childerhouse, P. and Towillet, D. (2003), "The impact of product life cycle on supply chain strategy", International Journal of Production Economics, Vol. 85 No. 2, pp. 127-140.

Alavi, M. and Leidner, D. (2001), "Review: Knowledge management and knowledge management systems: Conceptual foundations and research issues", MIS Quarterly: Management Information Systems, Vol. 25 No. 1, pp. 107-136.

Aloini D., Dulmin R., and Mininno V. (2010), "A Hybrid Fuzzy-Promethee Method for Logistics Service Selection: Design of a Decision Support Tool", International Journal of Uncertainty, Fuzziness and Knowledge Based Systems, Vol. 18 No. 4, pp. 345-369.

Aloini, D., Dulmin, R. and Mininno, V. (2013), "A Fuzzy Decision Support System for Drawing Directions from Purchasing Portfolio Models", in 19th Advances in Production Management Systems (APMS), Sep 2012, Rhodes, Greece, Emmanouilidis, C., Taisch, M., Kiritsis, D., Springer, IFIP Advances in Information and Communication Technology, AICT-398 (Part II), pp. 568-575, 2013, Advances in Production Management Systems. Competitive Manufacturing for Innovative Products and Services.

Becerra-Fernandez, I. and Sabherwal, R. (2014), "Knowledge Management: Systems and Processes", 2nd edition, Routledge, Taylor \& Francis Group.

Bensaou, M. (1999), "Portfolios of buyer-supplier relationships", Sloan Management Review, Vol. 40 No. 4, pp. 35-44.

Bensaou, M. and Anderson, E. (1999), "Buyer-supplier Relations in Industrial Markets: When do buyers risk making Idiosyncratic investments?", Organization Science, Vol. 10 No. 4, pp. 460-481.

Berger, P.D. and Zeng, A.Z. (2006), "Single versus multiple sourcing in the presence of risks", Journal of the Operational Research Society, Vol. 57 No. 3, pp. 250-261.

Birou, L., Fawcett, S.E. and Magnan, G.M. (1997), "Integrating Product Life Cycle and Purchasing Strategies", Journal of Supply Chain Management, Vol. 33 No. 1, pp. 23-31.

Brown, B. (1968). Delphi process: A methodology used for the elicitation of opinions of experts. Santa Monica: The RAND Corporation. An earlier paper published by RAND (Document No: P-3925, 1968, 15 pages).

Brun, A. and Pero, M. (2011), "Assessing suppliers for strategic integration: A portfolio approach", International Journal of Business Excellence, Vol. 4 No. 3, pp. 346-370.

Burke, G.J., Carrillo, J.E. and Vakharia, A.J. (2007), "Single versus multiple supplier sourcing strategies", European Journal of Operational Research, Vol. 182 No. 1, pp. 95-112.

Burke, G.J., Carrillo, J.E. and Vakharia, A.J. (2008), "Heuristics for sourcing from multiple suppliers with alternative quantity discounts", European Journal of Operational Research, Vol. 186 No. 1, pp. 317-329.

Caniëls, C.J. and Gelderman, C.J. (2007), "Power and interdependence in buyer supplier relationships: A purchasing portfolio approach", Industrial Marketing Management, Vol. 36 No. 2, pp. 219-229. 
Caniëls, C.J., Gelderman C.J. and Ulijn, J.M. (2010), "Buyer-supplier relationship development: An empirical study among Dutch purchasing professionals", Journal of Enterprise Culture, Vol. 18 No. 2, pp. 107-137.

Castillo, O. and Melin, P. (2008), "Type-2 Fuzzy Logic Theory and Applications", New York: SpringerVerlag, Berlin.

Cavinato, J.L. (1999), "Fitting purchasing to the five stages of strategic management", European Journal of Purchasing and Supply Management, Vol. 5 No. 2, pp. 75-83.

Chai, J., Liu, J.N.K. and Ngai, E.W.T. (2013), "Application of decision-making techniques in supplier selection: A systematic review of literature", Expert Systems with Applications, Vol. 40 No. 10, pp. 3872-3885.

Cox, A. (1997) Business Success-A Way of Thinking About Strategic. Critical Supply Chain Assets and Operational Best Practice, Earlsgate Press, Great Britain.

Cox, A. (2001), "Understanding buyer and supplier power: A framework for procurement and supply competence", Journal of Supply Chain Management, Vol. 37 No. 1, pp. 8-15.

Courtney, J.F. (2001), "Decision making and knowledge management in inquiring organizations: Toward a new decision-making paradigm for DSS", Decision Support Systems, Vol. 31 No. 1, pp. $17-38$

Curry, A., Flett, P. and Hollingsworth, I. (2006), Managing Information and Systems: The Business Perspective, Routledge.

Day, M.G., Magnan, M. and Moeller, M. (2010), "Evaluating the bases of supplier segmentation: A review and taxonomy", Industrial Marketing Management, Vol. 39 No. 4, pp. 625-639.

De Boer, L. (1998). Operations Research in Support of Purchasing -Design of a Toolbox for Supplier Selection. Enschede, Doctoral thesis, University of Twente.

Dong, W.M. and Wong, F.S. (1987), "Fuzzy weighted averages and implementation of the extension principle", Fuzzy Sets and Systems, Vol. 21 No. 2, pp. 183-199.

Drake, P.R., Lee, D.M. and Hussain, M. (2013) "The lean and agile purchasing portfolio model", Supply Chain Management, Vol. 18 No. 1, pp. 3-20.

Dubois, A. and Pedersen, A. (2002), "Why relationships do not fit into purchasing portfolio models: A comparison between the portfolio and industrial network approaches", European Journal of Purchasing and Supply Management, Vol. 8 No. 1, pp. 35-42.

Ellram, L.M. and Carr, A.S. (1994), "Strategic purchasing: a history and review of the literature", International Journal of Purchasing and Materials Management, Vol. 30 No. 2, pp. 10-18.

Emalgraby, W.J. (2000), "Supply Contract Competition and Sourcing Policies", Manufacturing and Service Operations Management, Vol. 2 No. 4, pp. 350-337.

Gallear, D., Ghobadian, A. and Chen, W. (2012), "Corporate responsibility, supply chain partnership and performance: An empirical examination", International Journal Production Economics, Vol. 140 No. 1, pp. 83-91. 
Gavrilova, T. and Andreeva, T. (2012), "Knowledge elicitation techniques in a knowledge management context", Journal of Knowledge Management, Vol. 16 No. 4, pp. 523-537.

Gelderman, C.J. and Van Weele, A.J. (2002), "Strategic Direction Through Purchasing Portfolio Management: A Case Study", Journal of Supply Chain Management, Vol. 38 No. 2, pp. 30-37.

Gelderman, C.J., (2003), A Portfolio Approach to the Development of Differentiated Purchasing Strategies. Eindhoven University of Technology, Eindhoven.

Gelderman, C.J. and Van Weele, A.J. (2003), "Handling Measurement Issues and Strategic Directions in Kraljic's Purchasing Portfolio Model", Journal of Purchasing and Supply Management, Vol. 9 No. 5-6, pp. 207-216.

Gelderman, C.J. and Van Weele, A.J. (2005), "Purchasing Portfolio Models: A Critique and Update", Journal of Supply Chain Management, Vol. 41 No. 3, pp. 19-28.

Gelderman, C.J. and Semeijn, J. (2006), "Managing the global supply base through purchasing portfolio management", Journal of Purchasing and Supply Management, Vol. 12 No. 4, pp. 209-217.

Gelderman, C.J., Semeijn, J. and De Zoete, R. (2008), "The use of coercive influence strategies by dominant suppliers", Journal of Purchasing and Supply Management, Vol. 14 No. 4, pp. 1-10.

Giebels, D., van Buuren, A. and Edelenbos, J. (2015), "Using knowledge in a complex decision-making process - Evidences and principles from the Danish Houting project's ecosystem-based management approach", Environmental Science and Policy, Vol. 47, pp. 53-67.

Hadeler, B.J. and Evans, J.R. (1994), "Supply Strategy: Capturing the Value", Industrial Management, Vol. 36 No. 4, pp. 3-4.

Hayes, R.H. and Wheelwright, S.C. (1979), "Link manufacturing process and product life cycle", Harvard Business Review, 37, pp. 133-140.

Hesping, F.H. and Schiele, H. (2016), "Matching tactical sourcing levers with the Kraljič matrix: Empirical evidence on purchasing portfolios", International Journal of Production Economics, Vol. 177, pp. 101-117.

Homburg, C. (1995), "Single sourcing, double sourcing, multiple sourcing...?", Ein ökonomischer Erklärungsansatz. Zeitschrift für Betriebswirtschaft, Vol. 65 No.8, pp. 813-834 (German text).

Hult, G.T.M., Ketchen Jr., D.J. and Slater, S.F. (2004), "Information processing, knowledge development, and strategic supply chain performance", Academy of Management Journal, Vol. 47 No. 2, pp. 241-253.

Kamann, D.-J. (2000), "Matrices, cubes and triangles in purchasing", in the Ninth International IPSERA Conference, London, Canada, pp. 1-6.

Kamann, D.-J. and Van Nieulande, V. (2010), "A four-filter method for outsourcing to low-cost countries", Journal of Supply Chain Management, Vol. 46 No. 2, pp. 64-79.

Kang, M., Wu, X., Hong, P. and Park, Y. (2012), "Aligning organizational control practices with competitive outsourcing performance", Journal of Business Research, Vol. 65 No. 8, pp. 1195-1201. 
Kang, M., Hong, P., Bartnik, R., Park, Y. and Changsuk, K. (2018), "Aligning purchasing portfolio management with sourcing negotiation styles", Management Decision, Vol. 56 No. 11, pp. 23412356.

Karjalainen, K. and Salmi, A. (2013), "Continental differences in purchasing strategies and tools", International Business Review, Vol. 22 No. 1, pp. 112-125.

Kilpi, V., Lorentz, H., Solakivi, T. and Malmsten, J. (2018), "The effect of external supply knowledge acquisition, development activities and organizational status on the supply performance of SMEs", Journal of Purchasing and Supply Management, Vol. 24 No. 3, pp. 247-259.

Knight, L., Tu, Y.-H. and Preston, J. (2014), "Integrating skills profiling and purchasing portfolio management: an opportunity for building purchasing capability", International Journal of Production Economics, Vol. 147 Part B, pp. 271-283.

Kraljic, P. (1983), "Purchasing must become supply management", Harvard Business Review, Vol. 61 No. 5, pp. 109-117.

Lau, H.C.W., Ning, A., Pun, K.F., Chin, K.S. and Ip, W.H. (2005), "A knowledge-based system to support procurement decision", Journal of Knowledge Management, Vol. 9 No. 1, pp. 87-100.

Lee, C.C. (1990), "Fuzzy logic in control systems: Fuzzy logic controller", IEEE Transactions on Systems, Man, and Cybernetics, Vol. 20 No. 2, pp. 404-418.

Liou, T.J. and Wang, M.J.J. (1992), "Fuzzy weighted average: an improved algorithm", Fuzzy Sets and Systems, Vol. 49 No. 3, pp. 307-315.

Liyanage, C., Elhag, T., Ballal T. and Li, Q. (2009), "Knowledge communication and translation - a knowledge transfer model", Journal of Knowledge Management, Vol. 13 No. 3, pp. 118-131.

Macris, A.M. and Georgakellos, D.A. (2010), "Ontology-based gap analysis for technology selection: A knowledge management framework for the support of equipment purchasing processes", Communications in Computer and Information Science, Vol. 112 No. 2, pp. 201-213.

Medeiros, M. and Ferreira, L. (2018), "Development of a purchasing portfolio model: An empirical study in a Brazilian hospital", Production Planning and Control, Vol. 29 No. 7, pp. 571-585.

Montgomery, R.T., Ogden, J.A. and Boehmke, B.C. (2018), "A quantified Kraljic Portfolio Matrix: Using decision analysis for strategic purchasing", Journal of Purchasing and Supply Management, Vol. 24 No. 3, pp. 192-203.

Nellore, R. and Soderquist, K. (2000), "Portfolio approaches to procurement: Analyzing the missing link to specifications", Long Range Planning, Vol. 33 No. 2, pp. 245-267.

Nemati, H.R., Steiger, D.M., Iyer, L.S. and Herschel, R.T. (2002), "Knowledge warehouse: An architectural integration of knowledge management, decision support, artificial intelligence and data", Decision Support Systems, Vol. 33 No. 2, pp. 143-161.

Nonaka, I. and Toyama, R. (2015), "The Knowledge-creating Theory Revisited: Knowledge creation as a Synthesizing Process", in Edwards, J.S., The Essentials of Knowledge Management, Palgrave MacMillan, New York, pp. 95-110. 
Olsen, R.F. and Ellram, L.M. (1997), "A portfolio approach to supplier relationships", Industrial Marketing Management, Vol. 26 No. 2, pp. 101-113.

Padhi, S.S., Wagner, S.M. and Aggarwal, V. (2012), "Positioning of commodities using the Kraljic Portfolio Matrix", Journal of Purchasing and Supply Management, Vol. 18 No. 1, pp. 1-8.

Pagell, M., Wu, Z. and Wasserman, M.E (2010), "Thinking differently about Purchasing Portfolios: An assessment of Sourcing", Journal of Supply Chain Management, Vol. 46 No. 1, pp. 57-73.

Porter, M.E. (1980), Competitive Strategy, The Free Press, New York.

Qu, S.Q. and Dumay, J. (2011), "The qualitative research interview", Qualitative Research in Accounting and Management, Vol. 8 No. 3, pp. 238-264.

Ramsay, J., (1996), "The case against purchasing partnerships", International Journal of Purchasing and Materials Management, Vol. 32 No. 4, pp. 13-19.

Ramsay, J. and Wilson, I. (1990), "Sourcing/Contracting Strategy Selection", International Journal of Operations and Production Management, Vol. 10 No. 8, pp. 19-28.

Rezaei, J. and Ortt, R. (2012), "A multi-variable approach to supplier segmentation", International Journal of Production Research, Vol. 50 No. 16, pp. 4593-4611.

Rezaei, J. and Ortt, R. (2013a), "Multi-criteria supplier segmentation using a fuzzy preference relations based AHP", European Journal of Operational Research, Vol. 225 No. 1, pp. 75-84.

Rezaei, J. and Ortt, R. (2013b), "Supplier segmentation using fuzzy logic", Industrial Marketing Management, Vol. 42 No., pp. 507-517.

Rink, D., Fox, R. and Harold, W. (2003), "Using the Product Life Cycle Concept to Formulate Actionable Purchasing Strategies", Singapore Management Review, Vol. 25 No. 2, pp. 1-7.

Ritter, T., (2000), "A Framework for Analyzing Interconnectedness of Relationships", Industrial Marketing Management, Vol. 29 No. 4, pp. 317-326.

Shadbolt, N. and Smart, P. (2015), "Knowledge Elicitation: Methods, Tools, and Techniques", in Wilson, J.R. and Sharples, S., Evaluation of Human Work, CRC press, Boca Raton, Florida, USA, pp. 163-200.

Sidharta, S.P., Stephan, M.W. and Vijay, A. (2012), "Positioning of commodities using the Kraljic Portfolio Matrix", Journal of Purchasing and Supply Management, Vol. 18 No. 1, pp. 1-8.

Sigglekow, N. (2007), "Persuasion with case studies", Academy of Management Journal, Vol. 50 No. 1, pp. 20-24.

Syson, R. (1992), Improve Purchase Performance, Pitman Publishing, London.

Terpend, R., Krause, D.R. and Dooley, K.J. (2011), "Managing Buyer-Supplier Relationships: empirical pattern of strategy formulation in industrial purchasing", Journal of Supply Chain Management, Vol. 47 No. 1, pp. 73-94.

Wagner, S.M. and Johnson, J.L. (2004), "Configuring and managing strategic supplier portfolios", Industrial Marketing Management, Vol. 33 No. 8, pp. 717-730. 
Wagner, S.M., Grosse-Ruyken, P.T. and Erhun, F. (2018), "Determinants of sourcing flexibility and its impact on performance", International Journal of Production Economics, Vol. 205, pp. 329-341.

Yin, R.K. (2013), Case Study Research: Design and Methods, 5th edition, Sage publications Inc., Thousand Oaks, California.

Zimmermann, H.J. (2013), Fuzzy set theory and its applications, 4th edition,

Boston/Dordrecht/London: Kluwer Academic Publishers.

\section{APPENDIX A}

Table A1. Roadmap details

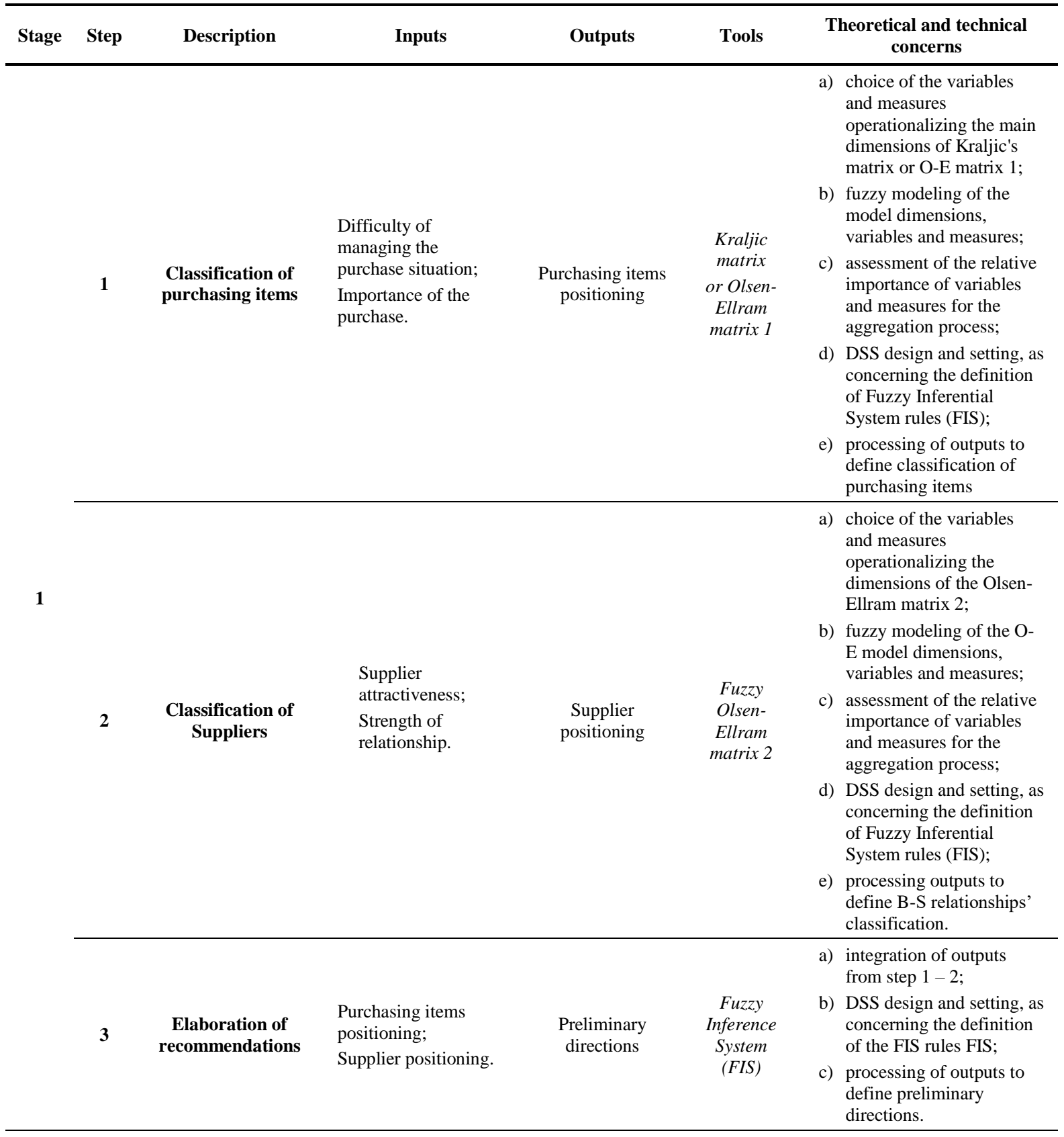




\begin{tabular}{|c|c|c|c|c|c|c|c|}
\hline \multirow[t]{2}{*}{2} & 4 & $\begin{array}{l}\text { Integration of } \\
\text { additional context- } \\
\text { related information }\end{array}$ & $\begin{array}{l}\text { Selection and } \\
\text { evaluation of } \\
\text { appropriate variables } \\
\text { (sources literature, } \\
\text { experience). }\end{array}$ & $\begin{array}{l}\text { Context-related } \\
\text { variables' } \\
\text { evaluations }\end{array}$ & $\begin{array}{l}\text { Focus } \\
\text { group; } \\
\text { Fuzzy } \\
\text { variables } \\
\quad \text { and } \\
\text { weights. }\end{array}$ & $\begin{array}{l}\text { a) } \\
\text { b) } \\
\text { c) }\end{array}$ & $\begin{array}{l}\text { choice of the additional } \\
\text { information to be } \\
\text { embedded into the model; } \\
\text { fuzzy modeling of the } \\
\text { additional dimensions, } \\
\text { variables, and measures; } \\
\text { assessment of the relative } \\
\text { importance of variables } \\
\text { and measures for the } \\
\text { aggregation process. }\end{array}$ \\
\hline & 5 & $\begin{array}{l}\text { Refinement and } \\
\text { Validation }\end{array}$ & Preliminary directions & $\begin{array}{c}\text { Feasible } \\
\text { recommendations }\end{array}$ & $\begin{array}{l}\text { Fuzzy } \\
\text { Inference } \\
\text { System } \\
(\text { FIS })\end{array}$ & $\begin{array}{l}\text { a) } \\
\text { b) }\end{array}$ & $\begin{array}{l}\text { DSS design and setting, as } \\
\text { concerning the definition } \\
\text { of the FIS rules; } \\
\text { refinement of preliminary } \\
\text { outputs to draw Feasible } \\
\text { Recommendations. }\end{array}$ \\
\hline
\end{tabular}

Table A2. Relative supplier attractiveness (adapted from Olsen and Ellram, 1997)

\begin{tabular}{l|c|c|c}
\multicolumn{1}{c|}{ Attractiveness factor } & Adopted & Weight 1 & Weight 2 \\
\hline Financial and economic factors & & & $\mathbf{. 1 5}$ \\
\hline 1. Supplier's margins & - & & \\
2. Supplier's financial stability & $\mathrm{X}$ & .5 & \\
3. Supplier's scale and experience & $\mathrm{X}$ & .5 & \\
4. Barriers to the supplier's entry and exit & - & & \\
5. Slack & & & $\mathbf{. 4}$ \\
\hline Performance factors & $\mathrm{X}$ & .5 & \\
\hline 1. Delivery & $\mathrm{X}$ & .35 & \\
2. Quality & $\mathrm{X}$ & .15 & \\
3. Price & & & $\mathbf{. 2}$ \\
\hline Technological factors & $\mathrm{X}$ & .3 & \\
\hline 1. Ability to cope with changes in technology & $\mathrm{X}$ & .4 & \\
2. Types and depth of supplier's current and future technological capabilities & - & & \\
3. Supplier's current and future capacity utilization & $\mathrm{X}$ & .3 & \\
4. Supplier's design capabilities & - & & \\
5. Supplier's speed in development & - & & \\
6. Supplier's patent protection & & & $\mathbf{. 1 5}$ \\
\hline Organizational, cultural, and strategic factors & - & & \\
\hline 1. Influence on the company's network position & $\mathrm{X}$ & .40 & \\
2. The internal and external integration of the supplier & - & & \\
3. The strategic fit between buyer and supplier & - & & \\
4. Management attitude/outlook for the future & - & & \\
5. Top management capability & $\mathrm{X}$ & .15 & \\
6. Compatibility across levels and functions of buyer and supplier firm & $\mathrm{X}$ & .30 & \\
7. General risk and uncertainty of dealing with the supplier & $\mathrm{X}$ & .15 & \\
8. Feeling of trust in relation with the supplier & & & $\mathbf{. 1}$ \\
\hline Other factors & $\mathrm{X}$ & 1 & \\
\hline 1. Ability to cope with changes in the environment & - & & \\
2. Safety record of the supplier & &
\end{tabular}

Table A3. Strength of the relationships (adapted from Olsen and Ellram, 1997)

\begin{tabular}{l|c|c|c}
\hline \multicolumn{1}{c|}{ Factor } & Adopted & Weight 1 & Weight 2 \\
\hline Economic factors & & & $\mathbf{. 4 5}$ \\
\hline 1. Volume or monetary value of purchases & $\mathrm{X}$ & .3 & \\
2. Importance of the buyer to the supplier & $\mathrm{X}$ & .35 & \\
3. Exit costs (and switching costs) & $\mathrm{X}$ & .35 & \\
\hline
\end{tabular}




\begin{tabular}{l|c|c|c}
\hline Character of the exchange relationship & & &. $\mathbf{3 3}$ \\
\hline 1. Types of exchange & - & - & \\
2. Level and number of personal contacts & $\mathrm{X}$ & .6 & \\
3. Number of other partners & - & - & \\
4. Duration of the exchange relationship & $\mathrm{X}$ & .4 & \\
\hline Cooperation between buyer and supplier & & &. $\mathbf{2 2}$ \\
\hline 1. Cooperation in development (R\&D) & $\mathrm{X}$ & .3 & \\
2. Technical cooperation (co-Design) & $\mathrm{X}$ & .3 & \\
3. Integration of management & $\mathrm{X}$ & .4 & \\
(logistics and production systems) & & & \\
\hline Distance between the buyer and the supplier & & & - \\
\hline 1. Social distance & - & - & \\
2. Cultural distance & - & - & \\
3. Technological distance & - & - & \\
4. Time distance & - & - & \\
5. Geographic distance & - & - & \\
\hline
\end{tabular}

Table A4. Table of rules (strategic/bottleneck items) (VL: VeryLow; L: Low; M: Medium; H: High; VH: VeryHigh)

\begin{tabular}{|c|c|c|c|c|c|c|c|}
\hline & \multicolumn{2}{|c|}{ O-E INPUTS } & \multicolumn{5}{|c|}{ O-E OUTPUTS } \\
\hline $\begin{array}{c}\text { Kraljic } \\
\text { Class }\end{array}$ & $\begin{array}{c}\text { Supplier } \\
\text { Attractiveness }\end{array}$ & $\begin{array}{c}\text { B-S Strength of } \\
\text { the } \\
\text { Relationship }\end{array}$ & $\begin{array}{l}\text { Strengthen the } \\
\text { relationship } \\
\text { (vs diversify) }\end{array}$ & $\begin{array}{c}\text { Improve } \\
\text { supplier } \\
\text { attractiveness }\end{array}$ & $\begin{array}{c}\text { Resource } \\
\text { (allocation) } \\
\text { level }\end{array}$ & $\begin{array}{c}\text { Investment } \\
\text { level }\end{array}$ & $\begin{array}{c}\text { Timing } \\
\text { horizon } \\
\text { (short/long } \\
\text { term) }\end{array}$ \\
\hline \multirow{25}{*}{ 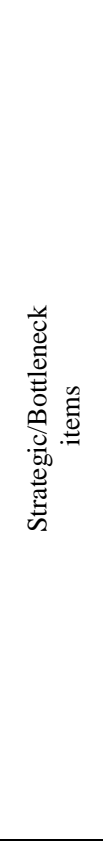 } & $\mathrm{VH}$ & VL & $\mathrm{VH}$ & VL & $\mathrm{VH}$ & VH & VS \\
\hline & $\mathrm{VH}$ & $\mathrm{L}$ & $\mathrm{H}$ & VL & $\mathrm{H}$ & $\mathrm{H}$ & $\mathrm{S}$ \\
\hline & $\mathrm{H}$ & VL & $\mathrm{H}$ & $\mathrm{L}$ & $\mathrm{H}$ & $\mathrm{H}$ & $\mathrm{S}$ \\
\hline & VL & $\mathrm{VH}$ & $\mathrm{L}$ & $\mathrm{M}$ & $\mathrm{L}$ & $\mathrm{M}$ & $S$ \\
\hline & VL & $\mathrm{H}$ & M & M & $\mathrm{L}$ & M & S \\
\hline & $\mathrm{L}$ & $\mathrm{VH}$ & M & M & $\mathrm{L}$ & M & $S$ \\
\hline & VL & VL & $\mathrm{M}$ & $\mathrm{M}$ & $\mathrm{M}$ & $\mathrm{M}$ & $\mathrm{M}$ \\
\hline & $\mathrm{L}$ & $\mathrm{L}$ & M & M & M & M & M \\
\hline & VL & $\mathrm{L}$ & M & M & M & M & M \\
\hline & $\mathrm{L}$ & VL & M & M & M & M & M \\
\hline & VL & M & M & M & M & M & M \\
\hline & $\mathrm{L}$ & M & M & M & M & M & M \\
\hline & M & M & $\mathrm{L}$ & $\mathrm{L}$ & M & M & M \\
\hline & $\mathrm{H}$ & $\mathrm{H}$ & VL & VL & M & M & M \\
\hline & $\mathrm{VH}$ & VH & VL & VL & M & M & M \\
\hline & M & $\mathrm{L}$ & $\mathrm{L}$ & $\mathrm{L}$ & M & M & $\mathrm{M}$ \\
\hline & $\mathrm{M}$ & $\mathrm{H}$ & $\mathrm{L}$ & $\mathrm{L}$ & M & M & $\mathrm{M}$ \\
\hline & M & VH & $\mathrm{L}$ & $\mathrm{L}$ & M & M & M \\
\hline & $\mathrm{H}$ & $\mathrm{M}$ & $\mathrm{L}$ & VL & M & $\mathrm{M}$ & M \\
\hline & $\mathrm{VH}$ & $\mathrm{H}$ & VL & VL & M & $\mathrm{M}$ & M \\
\hline & $\mathrm{H}$ & $\mathrm{VH}$ & VL & VL & M & M & M \\
\hline & $\mathrm{L}$ & $\mathrm{H}$ & $\mathrm{L}$ & $\mathrm{L}$ & M & M & $\mathrm{M}$ \\
\hline & M & VL & $\mathrm{H}$ & $\mathrm{L}$ & $\mathrm{H}$ & $\mathrm{H}$ & $\mathrm{S}$ \\
\hline & $\mathrm{H}$ & $\mathrm{L}$ & M & $\mathrm{L}$ & $\mathrm{H}$ & $\mathrm{H}$ & $\mathrm{S}$ \\
\hline & VH & $\mathrm{M}$ & M & $\mathrm{L}$ & $\mathrm{H}$ & $\mathrm{H}$ & $\mathrm{S}$ \\
\hline
\end{tabular}

Table A5. Inclusion and exclusion criteria

\begin{tabular}{cl}
\hline Factor & \multicolumn{1}{c}{ Detail } \\
\hline Budget constraints & Excluded because no significant budget constraints are imposed for the items; \\
\hline Uniformity constraints & $\begin{array}{l}\text { Included as Sustainability and Ethic policy fit, since the company strongly encourages } \\
\text { sustainability and ethic policies for suppliers' selection; }\end{array}$ \\
\hline $\begin{array}{c}\text { Product Life Cycle } \\
\text { (PLC) stage }\end{array}$ & $\begin{array}{l}\text { Excluded because all the products in the Renewable Energies Business Unit refer to the } \\
\text { same stage of the PLC; moreover, as concerning the purchasing items, they are a }\end{array}$ \\
\hline
\end{tabular}


fundamental part of any electronic product and they are stably and continually part of the whole company product portfolio. Due to these reasons, no relevant PLC-related distinctions were revealed;

Included because the company involves suppliers in co-design activities and has also set

Level of

concurrent/shared investments off co-investments both to support the R\&D process and to develop production planning and logistic processes more efficiently. This condition increases complexity and dependence, also expanding the switching costs which, in turn, reduce the opportunity to change the supply base quickly;

Level of resource currently allocated into Included, since the company has dedicated resources in the R\&D staff and in Purchasing the B-S relation and Logistics organizational units too;

Cross-supply level Excluded, as the suppliers are very specialized and supply several items exclusively. 